First published as Evans, K. and Robinson-Pant, A. (2010) Compare: exploring a forty year journey through comparative education and international development, Compare 40 (6), $693-710$

\title{
Compare: exploring a forty year journey through comparative education and international development
}

Karen Evans and Anna Robinson-Pant

And the end of all our exploring

Will be to arrive where we started

And know the place for the first time.

T.S. Eliot - Little Gidding - 1942

This special issue both completes and celebrates the $40^{\text {th }}$ volume of Compare.

We have been privileged to serve as editors of this important journal over the past six years. Both of us came to the role in 2004 and have completed our terms of office in 2009 and 2010 respectively. Part of the strict BAICE/Compare policy of appointing editors and all editorial members for fixed terms ensures a process of permanent renewal. Members of each incoming editorial team appraise the journal as they see it at the time. All do so from their own standpoints, perspectives, commitments and specialisms. This special issue has afforded us a rare opportunity to stand back and take a longer retrospective view, contacting past editors and inviting review and comment. We have experienced a journey back in time that has brought us to where we started, and in so doing we see the place differently, as for the first time. In this editorial, we share that journey with you, our readers.

How did we perceive the journal and the task before us, when first appointed in 2004? We were assuming responsibility for a journal in good health, with a committed worldwide readership and a unique position as the official journal of BAICE. We had, of course, outlined some views and intentions during the appointment process. As a first step, we expected submissions - individually or (in the case of Special Issues)

collectively - to have a stronger comparative dimension than was exhibited in many of the previous volumes. The comparisons could be systemic, historical, thematic, across subcultures or ways of learning; the main criterion being their significance for the international community of researchers and scholars. In this way we saw the journal as potentially able to incorporate work of a wider range of high quality educational research. As well as encouraging much more comparative analysis we wanted to ensure that important single country case studies, particularly in under-researched areas, became more strongly linked to wider themes of global or comparative significance. We also perceived a leaning towards articles on schooling in low and middle income countries. The profile of globally important research in lifelong learning and learning in organisations could be enhanced, as could the geographical spread. We considered that the balance between 'Western' and contextualised accounts should continue to be a critical concern, with more language support for authors as a contribution to countering the dominance of western modes of thinking and conceptualising. Most importantly, we wanted to re-position the journal in the field of scholarship research and practice, arguing for a more explicit positioning of Compare at the intersection of development studies, comparative education and what is loosely termed international education - both 
for identity of journal and for the promise of what might be achieved by a more dialogic approach.

In short, all aspects of the evolving character of the journal have been under review over the past six years. These perceptions, concerns and priorities resonated with custodians of the journal in BAICE and on the editorial board, who were also committed to the preservation of strengths while opening up new avenues and rethinking the position of the journal in the wider field. This $40^{\text {th }}$ volume celebration has generated perspectives, reflections and extended conversations that confirm the vibrancy of the journal and generate for us, great optimism for the future of the fields it represents.

The full-length articles open with an historical review of Compare and BAICE as its sponsoring association by Mark Bray, from his vantage point as former president of the World Congress of Comparative Education Societies (WCCES). Michela Chiara Alderuccio then provides an exploration of the link between the parallel discourses of education, economic development and the need to improve the quality of education. Daniel Wagner's contribution focuses on the ways in which international development agencies have moved beyond preoccupations with the quantity of education in developing countries towards an emphasis on the improvement of the quality of education, with a concomitant increase in the use of educational assessments as a way to measure, comparatively, gains and losses in quality. Wing-On Lee and Grace Mak's contribution explores the nature of foreign knowledge adaptation in China and the strategies adopted in turning it from 'submissive transfer to integrated knowledge' presenting an autonomous Chinese knowledge to the world for interaction on an equal footing in a diverse, global world. Theresa Lillis, Anna Magyar and Anna RobinsonPant contribute a critical account of Compare's mentoring programme for new writers, exploring how far an intervention such as this can attempt to challenge global inequalities in academic publishing. Robin Alexander's BAICE presidential address completes the set, critiquing the notions of 'world class' in education and underlining the responsibilities of the communities engaged in comparative and international education research. The set concludes with a short research note on the BAICE and Compare Archive by Michael Crossley and Keith Watson.

Bray's opening contribution highlights some of the ambiguities in the conceptualisations of comparative and international education and argues for stronger definitional and conceptual clarity. The second part of this issue comprises six shorter reflective contributions from writers differently positioned in the field, reflecting (but not in any sense representing) the interwoven perspectives and interests of different constituencies: Christopher Colclough, Robert Arnove, Cheng I-Hsuan, Mahesh Nath Parajuli, Mana Prasad Wagley, Gareth Williams and Angela Little. We asked these contributors to reflect on the overarching theme of this Special Issue: the evolving relationships between comparative education, international education, development studies and international development. First drafts were circulated to the other contributors and final versions were revised by each author in the light both of reviewer feedback and the other contributions. This exercise not only provides the epilogue for the $40^{\text {th }}$ Volume; it also offers a platform for an extended dialogue on these matters, as the Compare Forum develops [this new section of reflective pieces will be a regular feature in future issues of Compare]. In the book review section, Lore Arthur also explores how the term 'comparative' has been 
interpreted and Birgit Brock-Utne's and Terry Allsop's reviews highlight the ways in which a comparative perspective can contribute to teacher education and education in emergency situations.

\section{The development of Compare: perspectives from former editors}

As part of this exploration into the ways in which Compare has evolved over its forty years history, we decided to interview former editors of the journal about the direction of the journal during their time, their aims and the challenges they faced. A similar task was undertaken a decade ago by J.H. Higginson, who published a paper entitled 'The development of a discipline: some reflections on the development of comparative education as seen through the pages of the journal Compare'. By analysing explicit editorial statements and material in Compare, he charted the ways in which Compare editors had 'contributed to influencing the shaping and expansion of the concept of comparative education by their editorial selectivity' (Higginson, 2001:373) ${ }^{1}$. It is interesting to compare our starting point as editors - and those of the five former editors that we interviewed - with that of Higginson. Rather than focusing on how their/our 'editorial selectivity' influenced the journal's positioning within the field, all of us tend to emphasise that our own professional identities, values and aims need to be seen within the more complex interaction of other factors that also influenced the direction and evolving character of the journal. This determined how far we saw ourselves as proactive or reactive in the role as editor at any one time - a situation influenced by many external factors including the resources available, changes in academic publishing practices and differing priorities within higher educational institutions. In this section, we analyse some of the main influences on the current identity of Compare, from the insider perspective of previous editors.

\section{Defining Compare's scope and aims in relation to other journals in the field}

Looking back at the development of journals within the field of comparative education, there have been a range of sponsors who shaped their identities and - to a large extent formed their major audience too. The most senior journal - Comparative Education Review - is sponsored by the US Comparative and International Education Society and dates from 1957. As comparative education societies began to be established elsewhere in the world (see Bray et al 2007), other journals emerged - including Compare as the journal serving the British Association for International and Comparative Education and several others in the 90s, including Tertium Comparationis: Journal of International and Intercultural Comparative Education, sponsored by the German Society of Comparative Education (1997) and the Mediterranean Society of Comparative Education's Mediterranes Journal of Educational Studies (1996). In the UK, Compare was published soon after Comparative Education, which dates from 1964. Slightly younger was the International Journal of Educational Development (published by Pergamon Press since 1981). Started privately by two management consultants (the Ozanne brothers) who were keen to facilitate more critical debate on the development assistance (Dyer 2005), IJED was influenced by the growing consolidation of aid to

\footnotetext{
${ }^{1}$ Crossley, Broadfoot and Schweisfurth (2007:2) also set out to 'explore how the journal and their field have influenced each other over time' in their introduction to the volume celebrating the $40^{\text {th }}$. Anniversary of Comparative Education. McGrath's (2010: 537) recent thematic analysis of articles published over the thirty years in the International Journal of Educational Development had a somewhat different approach, aiming to answer 'How has the debate on education and development changed in the past 30 years?'
} 
development and strongly linked with the emerging UK Forum for International and Educational Training (UKFIET). Several key journals in this field were and are sponsored directly by development organisations - notably, the UNESCO journals International Review of Education and Prospects. Within the wider field of international development, several non-governmental organisations have also contributed to comparative educational debate through supporting academic journals, including Oxfam's Development in Practice (established 1991) and Gender and Development (from 1993). As the field of comparative education has evolved in response to theoretical innovation, particularly poststructural and postmodern conceptual debate (see Rust et al 1999: 88), new journals have also reflected these changing perspectives - an example being Globalisation, Societies and Education, now in its eighth year. Although each of the journals above had a distinctive character and stance, as Rust et al (1999: 108) point out, there is a danger in trying to pinpoint 'defining moments in the history of the field' through the material published: 'many who publish in comparative education journals may not even identify with the field and simply use the journals as an outlet for their research efforts'.

Former editors of Compare have been aware of shaping the journal, not only in relation to the field of comparative education and international development, but also needing to develop a distinctive identity in relation to the other academic journals in this area. Throughout its history, Compare's closest neighbours have been the other UK-based journals, Comparative Education and the International Journal of Educational Development as well as the US-based journal, Comparative Educational Review. As the other two UK journals are clearly associated with a specific field through their titles, Compare has long been assumed to sit between and to bridge the two fields, as Colin Brock (editor from 1988 to 1994) explained: 'I have always been strongly against a separation between what have come to be called Comparative Education and International Educational Development, and I see no reason why Compare should not continue to serve both interests, which are in any case interlocked. ${ }^{2}$ This position has meant that Compare has been faced with the challenge of potential overlap with both IJED and Comparative Education over the years, as Fiona Leach (editor from 1998 2001) pointed out: 'The boundaries between the three journals were very fluid, despite our different statements on aims and scope' ${ }^{3}$.

However all the former editors we interviewed had a clear notion of what made Compare different from the other journals in the field. Rosemary Preston (editor from 1998-2004) identified a 'seminal moment' at a major conference in 1989 when 'IJED emerged as very different from Compare and Comparative Education... with more of a focus on development practice and policy, ${ }^{4}$. IJED has continued to be seen as concerned more with countries in the South, accepting articles analysing development policy and practice, including one-country case studies. The current editor, Simon McGrath sees the relationship between education and development as 'central to the journal's focus' (McGrath, 2010: 543). Leach suggested that during her time as editor she did not think Compare interested practitioners particularly, whereas IJED did and appealed to a market of professional development people and DFID [Department for International Development]'. The differences in intended readership also had implications for IJED's initial review criteria, as Caroline Dyer (editor from 2001-2004) explained: 'Articles did

\footnotetext{
${ }^{2}$ Extracts are from e-mail correspondence with Colin Brock on 12/7/2010

${ }^{3}$ Quotations are from interview with Fiona Leach on 17/5/2010

${ }^{4}$ Quotations are from interview with Rosemary Preston on 28/5/2010
} 
not need an explicit comparative dimension: IJED required less academic contextualisation within the comparative literature since one clear audience was development policy communities'5. For Brock, the potential for Compare to explore the interconnections between 'developed' and 'developing' countries was an important reason not to restrict the journal in terms of geographical or geopolitical boundaries: 'It is obvious that one can indulge in comparative studies involving less developed countries as well as more developed ones, and in any case the issues of international educational development inevitably involve both donor and recipient states.'

There has perhaps been more overlap between Compare and Comparative Education, as both journals were primarily 'committed to European and US perspectives on comparative education and over time' (Preston) and were intended for a similar academic audience. Significantly, although both journals came to be published by the same company, with Comparative Education owned by the publisher, Compare was owned by BCES (British Comparative Education Society) which contracted the publisher. Under BCIES (British Comparative and International Education Society), Compare rose to three issues a year in the early 1990s and four issues in 2003 under BAICE. The journal sought to advance the field of comparative education and to inform members of society events. Although from the 1970s, Keith Watson and others ensured the publication of books from the BCES conference, Compare also carries one-off conference papers and compiled special issues on conference-related themes. Editorials have continued to carry society news, through the BCES, BCIES and BAICE periods ${ }^{6}$.

There were also clear differences in the ways that Compare and Comparative Education engaged with and positioned themselves in relation to the field of comparative education: 'Comparative Education was then beginning to adopt a role of reflection on comparative education as a field of enquiry, which was rarely explicit in contributions to Compare' (Dyer). Meanwhile, Compare was attempting to contribute to theoretical debate within comparative education from an alternative perspective, through inviting contributors to situate their material within the comparative literature (Dyer). This different approach could be seen as 'bottom-up', as Leach suggested: 'Comparativists are more interested in the theory of the system and the model. They believe by getting to grips with the theory we can better understand what happens on the ground. They are anxious to expand our understanding of the system in terms of the theoretical framework... The practitioners start with the data in the field, out of which they build a theory... It's a question of emphasis. Both want to contribute to theory on education around the world, though in different ways'. This was reflected in Compare's review criteria (and still is) and was also intended to broaden the journal's readership beyond the more academic 'comparativists': 'We were clear that every paper had to have an internationally comparative framework to contextualise the subject and to make the articles relevant to a very wide readership' (Preston). Dyer also emphasised that as editors, both she and Preston were 'particularly interested in comparative education papers which had applications within development' and to extend the historically more European focus of Compare. For the Reviews Editor too, there was the question of how far to review books outside the field of comparative education or, as Rose suggested, 'to accept books that had a broader perspective but that could be reviewed comparatively'.

\footnotetext{
${ }^{5}$ Quotations are from interview with Caroline Dyer on 20/7/2010

${ }^{6}$ See Crossley and Watson's note on the BAICE archive in this issue on the history of these societies.
} 
At this point, it is worth returning to Higginson's paper on the relationship between Compare and the field of comparative education - and the debates that he documents about how empirical research could contribute to theory building. He cites Peter Raggatt (editor of Compare in 1984) on the importance of 'educationists to stress the applied potential of the field ... such emphasis on applied studies should not result in the work being any less intellectually rigorous' (Higginson 2001: 377). Subsequent editors of Compare have similarly challenged the widespread assumption that practitionerorientated and applied research publications are of a lower academic quality than articles that engage more directly or explicitly with comparative educational theory. This implicit separation and hierarchical relationship between 'theory' and 'practice' has been reinforced in recent years by the indicators of 'quality' shaping academic institutions worldwide (such as the UK Research Assessment Exercise where 'practitioner' research publications have tended to be rated as lower status). Having situated the journal in relation to IJED with its 'development policy and practice' agenda, Compare's editors had adopted a more explicit commitment towards working for positive change than might be expected from a journal in comparative education. As Dyer commented: 'Comparative education is concerned with looking at an international literature, like development, but not necessarily with the same agenda for change'.

As Mark Bray notes in this issue, the name of Compare recently changed to include 'international' as well as 'comparative' in its subtitle. This decision was taken at an editorial board meeting when we realised that 'a journal of comparative and international education' would be more appropriate than 'a journal of comparative education'. This alteration to the journal title was not seen as changing our direction or content at the time, as Pauline Rose (Reviews Editor from 2003 - 2008) recalls ${ }^{7}$ : 'I had assumed that the journal was always called 'International and comparative education' in line with the name and remit of BAICE... Language is important but the issue is ultimately what we are trying to achieve. If people saw Compare as being only comparative in the narrow sense of how some understand it, it would be limiting. From the outset, Compare has been about development too and we changed the name to reflect what was already there in terms of the content - and in recognition of the strong link with BAICE. It was about what we were already doing., 8

Looking at how Compare has developed a distinctive identity, its ongoing dynamic relationship with Comparative Education and IJED has helped to define the journal's scope and influences its range of authors and readers. As Rose pointed out: 'It seems a strange divide, to see people and for people to see themselves as either comparativists or development specialists... Compare has tried to bring these together and encourage people to see the intersections between comparative education and development. It is an ongoing challenge to overcome this false divide'. It is also apparent that the ways in which the world has changed since 1970 have also influenced Compare - in intellectual and practical ways. Compare began to respond to new understandings of comparative education and of international development - in terms of positioning itself within these fields. As the concepts of 'nation' and 'national' could no longer be taken as given and began to be problematised in this changing context, Compare editors expanded their criteria for review - as Bray discusses in his article on comparative education, 'although

\footnotetext{
${ }^{7}$ Quotations are from interview with Pauline Rose on 10/8/2010

${ }^{8}$ Bray notes that Compare reversed the order of 'international' and 'comparative' as compared to BAICE: from the editors' recollection, the decision was made to put the word 'comparative' first only because it appeared to flow more logically and we were adding 'international' to our earlier subtitle.
} 
comparison of national systems of education has been a traditional focus... a strong case can be made for many other units for comparison including times, cultures, values and ways of learning'. As we will explore later in this editorial introduction, the definitions of comparative education, international education and international development were and are continually evolving and Compare's development can be seen as a response to such changes in the wider field.

\section{Material influences shaping Compare's identity}

Alongside these changes in the discursive field within which Compare situated itself, former editors emphasised above all the many practical and material factors that both constrained and offered opportunities for shaping the journal in a particular direction. In the journal's early life, a major issue facing the editors was how to increase the flow of quality material and to make sure Compare came out on time. Leach emphasised that that for her as editor, 'quality was more important than whether it sat neatly within a certain field'. At this time, the editors' own contacts, networks and interests greatly influenced the range of authors submitting to the journal, including the geographical spread. Due to their own professional backgrounds and interest in developing countries, Dyer and Preston consequently 'became concerned that Compare was not appealing sufficiently to comparativists working on Europe and other post industrial parts of the world' and for this reason looked to appoint a European specialist (Karen Evans) when Preston completed her term as editor. In recent years, the number of high quality submissions has increased substantially and, as Bray notes (this issue), Compare expanded to six issues a year in 2009 in response to the greater number of articles queuing for publication. The increasing popularity of the journal with contributors is no doubt due to these editors' active promotion of Compare, as Preston recollects: 'I think that carefully publicising the journal at conferences was a good thing, for instance at the big CIES meetings in the US... It was fun on the platform with the other journal editors, collectively getting across the information about journal editing and publishing processes, at the same time as attracting authors by highlighting the virtues of Compare'.

As the journal of a membership organisation (BAICE), Compare started life as the biannual bulletin of the British Comparative Education Society (BCES) - the forerunner to the British Comparative and International Education Society (BCIES) (Preston). BAICE was formed in 1997 from the merging of BCIES with the British Association for Teachers and Researchers in Overseas Education (BATROE) and in these days, Compare had a strong readership within teacher education (ibid). Preston identified the development of a strong relationship with the publisher and with BAICE as key influences on the development of the journal: 'The main thing I learned through editing Gender and Education and then Compare was the importance... of developing an understanding of how to realise the scope for good relations with the publisher and how this can be used to enable a journal to grow'. Initially, there was resistance from the Compare editorial board to the idea of Taylor and Francis paying anything more to the journal than postage costs, for 'fear of ceding the autonomy of the journal to the publisher' (Preston). However, a new contract was negotiated which accorded royalties to BAICE as the owner of the journal, from which money was withheld to enable the editors to secure efficient administrative support. With these resources, Compare was in a position to develop a more rigorous review system and tighten its expectations of the editorial boards. With the new contract there was the possibility of strengthening the 
administration of Compare and its relationship with its parent body, BAICE. In inviting the BAICE Chair to be ex officio the Chair of a more formalised Board, the BAICE Executive and membership became much more fully aware of the significant expansion of Compare and the opportunity it offered for publishing the work of members. As Compare's circulation has increased over the years, it should be noted that 'the significant and rising royalty payments have consolidated BAICE financially for over a decade, in a way hitherto unprecedented' (Preston).

This process of professionalising the journal involved bringing new groups of people into the editorial boards and reviewer database. Preston described how they ensured a 'balance of comparativists who worked conceptually and in less developed parts of the world' and that they 'developed the International Advisory Board as a branding device to attract new international audiences'. The process for submitting and reviewing articles became more systematised following the best practice of the 1990s. Initially, as Dyer explained, 'it was a case of organising the whole peer review process electronically to develop a wider and better organised reviewer base, with records of how many people had done reviews and how often'. The editors also monitored the quality and approach of reviews they received - 'not asking again people who sent very short or unconstructive reviews' (Dyer). This attention to the educational and developmental role of an academic journal has influenced Compare's ethos and inspired the development of our mentoring programme for new writers (see Lillis et al in this issue). As Preston commented: 'Learning the rules about what it takes to make a polished professional journal is important. I was recently made aware of the concerns of the editors of a younger European journal, wanting to protect authors from destructive reviewers, who hadn't yet understood that their role is one of professional development, nurturing the next generation of scholars, not discouraging them'.

Electronic communication has improved the speed and ease with which authors and reviewers can communicate with Compare, yet the current editors are still faced with challenges similar to the previous editors regarding the need to ensure that the journal reaches a wider audience. As Dyer reflected on her time as editor: 'I found the lack of a Southern voice in the journal regrettable and it was difficult to find a way around this'. Leach also noted the imbalance in articles submitted to Compare: 'We always have more submissions from those who must get published because of the pressure from the RAE and who work in knowledge-rich environments. The tension is around encouraging researchers working overseas who want to get published but are often not able to produce to such tight schedules'. As many academic journals move to a system of online submission, Compare is now having to decide whether taking this step would contribute to narrowing or widening the gap between writers from different parts of the world and the possible impact on our reviewing processes. Former editors expressed concerns that with an online submission system, the 'peer review process might lose that personal touch', making it even more difficult for editors to persuade reviewers to respond to their requests. Preston warned that the new electronic submission and reviewing practices could have implications for the roles and relationships between authors, reviewers and editors: 'I sometimes feel the electronic form of submission with its regulatory frameworks is undermining the creativity and professionalism of both editors and reviewers'.

How do the challenges differ now? 
Comparing the experiences of Compare editors through its recent history, in some respects the challenges seem quite similar - the ongoing tensions around ensuring high quality articles, timely publication and a better balance of contributors to include those from the global South, practitioners and policy makers as well as researchers. However it is also clear that the five editors we interviewed were actively engaged in developing and consolidating the management, reviewing and 'outreach' procedures that have ensured Compare has become regarded as 'one of the leading journals internationally in the field of comparative education' (Hayhoe, 2007, correspondence to publisher).

Discussing the differences today, several editors noted the proliferation of educational journals - 'keeping up with them is more of a challenge for the editors and working out how to retain that competitive edge' (Dyer). There is also a sense of how journals are now read and used differently and the need for the editors to take these reader expectations into account - Preston pointed out that 'nowadays you don't read a journal from cover to cover, you do a search according to the topic on which you are writing'.

In discussion of the external influences on Compare (and other journals), higher educational policy - particularly the RAE in the UK- has greatly influenced the number and kinds of articles submitted. With the shrinking research funding in the UK and elsewhere, Leach suggested that that in the future there may be 'less interest [from funders] in blue skies research', with the emphasis on presenting evidence of research 'impact' - which will in turn 'permeate the research agenda and influence what people write'. This could raise new questions for Compare about its aims and scope: 'Should Compare position itself as a journal gathering new knowledge which has practical use and be explicit about this now?' (Leach) Looking back to the discussion about Compare's changing relationship and identity in relation to other journals in the field, we may again be entering an era when comparative education is emphasising its 'applied' potential.

\section{Definitions and domains: to whom do these distinctions matter, and why?}

The set of six short reflective papers on the intersections of comparative education, international education, development studies and their implications for education development bring into focus the challenges and the promise for Compare as it moves towards its first half-century. In positioning these articles at the end of this special issue, they also provide a fitting epilogue for this $40^{\text {th }}$ Volume as a whole. The writers reflect different academic traditions and career stages - early career to emeritus professor - and from different regions of the world. They were invited to reflect on the distinctions and relationships that are salient for them. So, for example, Colclough compares traditions and assumptions embedded in the distinct academic fields of Development Studies and Comparative Education in contrast to Arnove, who discusses the contributions of Comparative Education to international development. I-Hsuan Cheng approaches the question from the standpoint of an early career researcher constrained by convention, benchmarking to international standards and the perceived 'gold standard' in comparative education; both Cheng and Parajuli \& Wagley are involved in the process of building up new departments in Taiwan and Nepal respectively. Parajuli and Wagley also highlight the barriers that the traditional compartmentalization of subjects such as 'education' and 'development' has erected. Williams writes from the perspective of an economist and positions himself as outsider as far as the academic 'tribes' of comparative education are concerned. Angela Little rounds off the set in a broad 
overview that asks 'to whom do these distinctions matter, and why', pointing out that it is what scholars actually $d o$ that really matters. As editors of this special issue, we deliberately did not insist that they all did the same - the discussion is also about the terms that are most important for each of the writers. The contributions are thus socially positioned according to where the writer stands in the landscape and what the landscape features mean from his or her own standpoint.

\section{INSERT Figure 1 ABOUT HERE}

Significant overlaps and creative tensions are apparent at the interface of comparative education and development studies, in which distinctive bodies of theory inform and shape different strands of research and discourses of scholarship. As Colclough observes, the range of valid questions that can be addressed is very broad in both fields and 'what count as valid answers' has changed significantly for specialists in both fields. From Colclough's perspective, comparative education is 'principally interested in examining and explaining the characteristics and effects of education systems in different national, historical and cultural contexts' while development studies are 'mainly interested in understanding economic and political change in lower income countries and the changing relationships between these countries and the rest of the world'- a view consistent with the definition adopted for the UK Research Assessment Exercise in UK Universities. The major distinction, from this perspective, is the underlying concern of development studies with the eradication of poverty while comparative education, as a field of scholarship and inquiry, is not perceived fundamentally to be shaped by specific commitments to the evolution to a more desirable state of society.

Within comparative education, of course, there are easily traceable debates and creative tensions between approaches; competing discourses have been dominant at different times; between the pursuits of generalisable scientific principles or contextualised understanding; between the purposes of policy borrowing, problem solving or helping educators in the 'imagination' of different ways of doing things. Arnove, as a comparativist, contests the 'development-free' view, arguing strongly that there are indeed development assumptions in much comparative education work. For example, in the post-war years attention turned towards a better understanding of the relationship between educational achievement and economic development, a trend in comparative studies that was given a further impetus in the 1980s by largely policy-driven interests in understanding the role education was playing in the growing Asian economies. New foci of interest emerged against a backcloth of diversification of topics. This has often involved a rethinking of methodology and units of comparison, beyond and different from those of nation state and national systems of education, as mentioned previously.

Bray and Thomas (1995) set out the case for multilevel analysis in comparative education while Evans (2003) made the case for layered studies that include city regions, labour markets and local cultural identities intra-nationally as well as crossnationally, particularly in research into adult learning and education beyond schooling. Hayhoe promoted cross-cultural studies in ways which challenged uni-linear modernization theories (see for example Hayhoe and Pan 2002). With growing diversification also came a search for boundaries: could a theory of method be found 
that would define and distinguish a field that was already very dispersed in content, and which could, some feared, lose its identity? This question, still very much alive, has generated heated internal debates, particularly among British comparativists but extending far beyond them, from the 1960s onwards. A review of the contents of the journal Prospect and the debates at the World Congresses of the time highlight this (see Bray et al, 2007), while Broadfoot (1999) took the debate forward more recently in her observations of the danger of the field being perceived as little more than a 'pot-pourri' of topics linked only by the variety of their national settings'. The desire to distinguish research and scholarship in the Comparative Education field from research perceived as applied and developmental also dies hard. The editor of the International Handbook of Comparative Education (2010) has restated the argument for comparative education to be seen as distinct from any notion of development towards more desirable states, suggesting that, in comparative education, seen as a discipline, historical comparative research into education in pre-modern times is inherently as valuable and significant as comparative education studies that focus on more recent historical trends and contemporary issues (Cowen and Kazamias 2010.)

So the extent of the overlap between domains is minimized by some, maximized by others. Yet it is not clear, where, in and among these overlapping domains, we are to locate the work of education academics who carry out cross-national studies in their own particular specialist fields, such as Higher Education (HE) or Vocational education and Training (VET). As Raggatt argued many years ago (1984), these fields are also informed by diverse disciplines and theoretical frameworks from which comparative education could learn. Gareth Parry brought this debate back into focus in a recent BERA seminar ${ }^{9}$, in posing a question to the speaker (Karen Evans): whether 'comparative education and comparative higher education are semi-detached territories, with not much traffic between them in terms of theory and method?' So far, the domain of International Education, although strongly signalled in the sub-title of Compare - a journal of comparative and international education - has featured little in the discussion. This is often seen as the communicative domain of inter-cultural education, with a focus on mutual learning and exchange (See Figure 1). Yet international education, in its larger sense, has very significant overlaps with the 'global dimension' of comparative education, according to Arnove: education that links researchers, teachers and often students internationally in analysing common problems and sometimes in action to combat 'social ills affecting individuals and communities across borders.' Little sees international education as the unifying mission for scholars, embracing the practices of analysis, advocacy and activity. Through their commitment to international education, participants in a wide range of international partnership projects have potentially productive overlaps with those committed to comparative education and development studies. They also have much to contribute to 'sharing best practices', and possibly also to stimulating greater interest in pedagogical research, a need identified in Alexander's presidential address.

So we return to the more fundamental question: 'To whom do these distinctions matter and why?' The short answer is that they matter to scholars concerned with how they are positioned and recognized. They matter for identities, status and careers. The barriers, and the struggles they engender, are enduring. They are apparent, for example, in the

\footnotetext{
${ }^{9}$ Question posed at the British Educational Research Association Seminar: Comparative xxx held at the University of Bedfordshire, May 2010
} 
accounts of I-Hsuan Cheng, as an early career researcher, and Williams as an emeritus professor. The distinctions also matter for journals seeking (and competing) to define and evolve their domains, as we outlined with regard to the history of Compare. Journal surveys carried out over the past thirty years are reflections of the importance attached to scoping the fields and mapping trends. Lee and Mak's full-length article provides a new example, reporting on a bibliometric analysis of the entries in the last nine years (2001-2009) in prominent journals in China, to chart the evolving nature of the field. Colcough, in his reflective analysis of published articles in English language journals between 1993 and1996 and the patterns which emerge when they are compared with those published a decade later, in the years 2003-2006, draws attention to the increased openness to 'the broader canvas' of education-society interactions in both Comparative Education Review and International Journal of Education Development. Over this same period there was little apparent shift in poverty/human development focus and attention to low income countries dropped in the subset of journals reviewed. Compare has aimed to offset this with explicit openness to articles focusing on under-researched societies, many of which fall into the low income category. In the early 1990s, articles in the journals included in the survey tended to focus on education policy and reform, literacy, public financing, teaching practice effectiveness and roles. More recently (2003-6) more articles have concentrated on globalization and its effects, decentralisation, cultural diversification, gender and society - which Colclough interprets as evidence of a greater overlap between the interests of specialists in comparative education and those in development studies since the turn of the century.

\section{So are there dangers of over-emphasising differences between apparently converging fields of endeavour?}

Little's contribution asks 'what's in a name?' and emphasizes the importance of looking at practices. When we look at what international scholars actually do, we see that there are no monopolies. Development studies and studies of international development in education focus on change enhanced by good analysis and quality of analysis enhanced by comparison. It is therefore self evident that comparativists do not have a monopoly on systemic and scholarly comparison. Similarly, neither development studies nor international studies of educational development have a monopoly on change and advocacy; nor does international education have a monopoly on the pursuit of intercultural understanding, according to Arnove. In setting out three defining dimensions for his version of comparative education, the extent of the overlaps and intersections become apparent:

- a scientific dimension: the better the theory and the more inclusive the levels of analysis, the more robust the insights and conclusions.

- a practical and ameliorative dimension: 'informing and improving educational policy and contributing to greater international understanding'.

- a global dimension: nurturing critical conscience, analytical abilities, ethical sensibilities and tolerance of diversity - 'contributing to greater well-being across the globe.' 
It has been possible to include only a selection of voices here; there are many others with important things to say, for example from the perspectives of practitioners in NGOs and policy makers in international organisations. The perspectives and ideas voiced here offer departure points for an extended dialogue on these matters.

\section{Towards a more dialogic approach.}

So where do we find common cause(s), to anticipate Colclough's question? At the highest level of abstraction, all domains are concerned with the human condition. Many who identify with these fields in different ways so find common cause in the practices of analysis, advocacy and activity, as Little observes. There is a perception (which recurs throughout the former editors' interviews and the reflective articles) that overdifferentiation of domains has cursed rather than benefited the endeavours of those who work within them. One response to this is to seek a portmanteau definition of international education that embraces all. A different response, which is prefigured in Figure 1, is to celebrate differentiation in traditions and perspectives while seeking a more dialogic approach in which mutually respected traditions and perspectives enrich and illuminate each other and, ultimately, what scholars do in practice. There are examples from other fields of social science, if we can look beyond our immediate preoccupations to find 'the stones from other hills that may help to polish ours', to cite Broadfoot (1999). Charles Ragin (1991) a comparative sociologist seeking a way of overcoming the equivalent of paradigm wars in international sociology, rose above these distinctions to develop an approach which combined discourses on cases and on variables and developed new insights and explanations through the construction of extended dialogue between ideas and evidence. There is much scope for constructing rich extended dialogues between ideas, evidence at the intersection of the domains labelled and differentiated as comparative, international and development studies in education and extending these to extended dialogues to questions of practice.

Alderuccio's paper on Mozambique, for example has reflected the complexity of curriculum transformations in SSA, in investigating 'the dialogue as well as the contradictions between global and local educational agendas'. This study uses its structure and methods to move the discourse from global and general issues on curriculum transformation to specific and local issues. Parajuli and Wagley also refer to the challenges of breaking the hegemony of received discourse with overcoming the compartmentalisation of fields of study. I-Hsuan Cheng concludes that, in taking social responsibility towards the international community, researchers need to participate in the 'embedding of the research practices of international development in the discourse of comparative education', whilst also emphasizing mutual respect in communications between researchers of different disciplines.

As scholars with differentiated interests and perspectives move within fields that increasingly intersect, we need to ask whether a more dialogic approach could indeed produce what Alexander calls for in his BAICE Presidential Address: greater take-up of ideas from Type III (majority of academic comparative studies) combined with better interpretations of findings from Type I (large scale international surveys of educational outcomes) and Type II (policy-related studies). Wagner's contribution exemplifies the potential for cross-fertilisation, in the field of assessment studies. All assessments seek comparability, but in different ways: international and regional indicators are aimed at cross-national comparability, while hybrid assessments, more focused on local contexts, 
offer other kinds of comparability. Their relative significance, Wagner, agues, depends on the policy goals desired.

Furthermore, we need to recognize the temporary nature of periodic 'settlements' over what it is important to know more about at any particular time. All writers remind us of the need continuously to question the export of western assumptions, a stance that also has strong implications for the languages in which we work. Williams' contribution, in particular, draws attention to the ways in which language, and in particular proficiency in only one language, can come to dominate thinking about education and culture. As in other academic fields siloed, self-referential research communities fragment the field, yet they are also productive in generating sustained discussion and challenging perspectives. Sustaining productive differentiation while generating greater crossfertililization through dialogue avoids the undifferentiated melting pot or the "pot pourri' feared by Broadfoot (1999) and many others. The overlaps are considerable, whether they are acknowledged or not. In all domains there are robust (and less robust) lines of research inquiry. Robust lines of research inquiry in the wider social sciences, moving again beyond the self-referential debates and adapting Sawchuk's (2010) criteria, embrace 'more whole' rather than 'less whole' models of education-society interactions; they have clearly articulated theoretical frames of reference and traceable genealogies in previous work; they are informed by empirical evidence which offers challenges to mechanistic or partial views of reality; and they engage with the inherently value-laden or political nature of education and learning. A dialogic approach means constructing extended dialogues between ideas and evidence in the intersections and overlaps, recognising, respecting and learning from robust lines of inquiry where they conflict as well as where they converge.

\section{Compare: the way forward}

As we reach Compare's $40^{\text {th }}$ Anniversary and look towards the future, it is worth recalling the words of Martin McLean, a former editor, who suggested that 'risk taking has been one of the characteristics of successful comparative educationalists' (in Higginson, 2001: 377). Having established a significant voice within both comparative education and international development and consolidated sound management and editorial procedures, Compare is now in a strong position to reflect on where to go next. During the recent years, we have attempted to respond to previous editors' concerns regarding the imbalance of contributors from different parts of the world by developing the Compare/BAICE new writers' programme. As Yusuf Sayed, current editor of Compare, emphasised, this will continue to be a major priority: "we need a more diverse pool of writers writing for the journal - in particular, we need to have authors who challenge the conventional orthodoxies and hegemony of journal production'. Although the mentoring programme has gone some way to helping some scholars to publish in Compare through introducing them to the expectations and practices of a 'centre' based journal, there is still a need to interrogate further Compare's publishing practices through the lens of the 'geopolitics of academic writing' (Canagarajah 2002). An example is the priority given to the citation indices by UK and US higher educational institutions, which has meant increasing pressure for scholars in these countries to publish in journals that are high on the Social Sciences Citation Index. Whilst Compare recognises the importance of regaining this status in the near future, we are also faced with dilemmas related to our aim of tackling inequalities in publishing (as discussed by 
Lillis et al in this issue). At present a high rejection rate of articles and strong numbers of citations in US journals are the key indicators of success in such indices - measures that do not take account of citations in regional or national journals in the countries where many of our contributors and editorial board members are based and could be seen to contradict the value we place on broadening our author and reader base.

As well as responding to changing academic institutional practices, we are aware of the need to analyse the ways in which journal reading, writing and reviewing are constantly evolving in response to digital literacies and associated new communicative practices. As former editors pointed out in the second section of this editorial, we now rarely read a journal from cover to cover, and the relationships between editor, writer and reviewer are becoming shaped by the new technologies being introduced by publishers for submission and reviewing processes. Looking back at the forty years of Compare, it is surprising that the form of journal articles has remained relatively consistent and rarely varied. Most of our authors follow the conventional expectations of a research article (see Swales 1990), consisting of research problem/question, literature review, data analysis, discussion and conclusion. There have been exceptions - notably when authors have adopted a narrative research approach (see the special issue edited by Sheila Trahar in 2008: Vol. 38/3, 'Narrative methodological approaches: their contribution to comparative and international education'). Perhaps we are now at a point where we can encourage more innovative writing in terms of form and approach (both in terms of our authors and reviewer responses). In his ethnographic study of academic literacy practices at the University of Jaffna in Sri Lanka, Canagarajah $(2002 ; 294)$ identified ways in which some of his colleagues had 'developed writing strategies that have the potential to construct hybrid textuality': they 'code-switch between a temporally organized text for the local audience and a spatially/abstractly organized text for the center audience'. With so many of its reviewers and authors writing within what Rizvi (2010) has termed 'transnational spaces', Compare is in an ideal position to encourage the development and publication of such 'hybrid' texts within the journal.

Looking into the future, there may be the opportunity for Compare to make greater use of new technologies - not just in terms of our management systems - but in publishing electronically in a form that goes beyond our current conventional text-based articles. This would seem an appropriate path for Compare, as a journal seeking not to privilege dominant knowledges, particularly with regard to academic literacies. Experimenting with the shape of our journal may also enable us to engage with new audiences and writers - thus taking forward current initiatives such as Compare Forum, which is intended to offer a space for policy makers and practitioners to write in a form less constrained than the traditional research-based article.

Finally, the most important question for our future is how to retain and build on Compare's unique position as a journal at the intersection of comparative education and international development. Here it is worth examining what exactly Compare has to offer each of these fields. Looking at international development, Caroline Dyer suggested that 'people working in international development tend to have rather unnuanced views about education, are over-convinced about human capital and are unfortunately rarely reading enough of the comparative education journals which talk about the complex and contradictory world of education'. Compare articles which explore educational issues and practices within development contexts and in relation to development debates can contribute to opening this 'black box' for those working 
outside education. In 1999, Rust et al (1999: 107) noted in their analysis of research strategies in comparative education that 'the journals Comparative Education Review, Comparative Education and International Journal of Educational Development ${ }^{10}$ devote minimal space to methodological issues in the field'. Looking at today's journals, by contrast there appears to be much more debate and transparency about methodology. The inclusion of a comparative and reflexive perspective in terms of the insider/outsider perspective that many of the writers in Compare bring to their analysis of development interventions also contributes a greater understanding of the complexity of relationships than is often apparent in some development studies journals. The attention to 'who' is doing development, whose theories are informing the analysis and to exploring processes of learning through development (as opposed to analysing only 'education and development') has been particularly apparent in recent articles looking at collaborative research and development projects. With the movement towards funding more cross-continent collaborative and 'capacity building' projects (such as the UK Department for International Development's Research Programme Consortia), it is likely that this kind of reflexive cross-cultural analysis will gain greater prominence in the pages of Compare.

Looking at Compare's potential to contribute to the field of comparative education, we take inspiration from Watson's (2001: 36) question and answer: 'In what ways could comparative educationists help to suggest and pioneer new approaches to education? New ways of funding education have been studied comparatively, but new ways of learning and teaching are growing apace'. At a time when - as current editor, Paul Morris, suggests 'there is something of a resurgence of interest in Comparative and international education which is largely a by product of the growth of international league tables, policy borrowing and policy initiatives being primarily justified by reference to what goes on elsewhere' - there seems to be an even greater need for understanding of the processes of intercultural learning and interaction, the "new ways of learning and teaching' signalled by Watson a decade ago. The gradual shift towards 'intercultural' rather than 'cross-cultural' exploration in Compare could point to the new contribution that the journal could make in future to comparative education debates. This might provide a more critical perspective on the intercultural processes involved in the transfer of educational systems of governance and accountability, pedagogies and educational concepts in the context of our increasingly interconnected world - and help to ensure that any such change is for the better.

\section{Acknowledgements}

We would like to thank all the former editors of Compare who contributed greatly in terms of the interviews and their critical input to drafts of this editorial.

\section{References}

Bray, M., B. Adamson and M. Mason eds. 2007. Comparative education research: Approaches and methods. Hong Kong: Comparative Education Research Centre, The University of Hong Kong, and Dordrecht: Springer.

\footnotetext{
${ }^{10}$ Compare was not included in this analysis as 'it might bias the study excessively toward the British arm of the field' (ibid: 90).
} 
Bray, M., M. Manzon and V. Masemann 2007. Introduction. In Common interests, uncommon goals: Histories of the World Council of Comparative Education Societies and its members. eds. V. Masemann, M. Bray and M. Manzon, 1-12. Hong Kong: Comparative Education Research Centre, The University of Hong Kong, and Dordrecht: Springer.

Bray, M. and R.M. Thomas 1995. Levels of comparison in educational studies:

Different insights from different literatures and the value of multilevel analysis. Harvard Educational Review 65, no. 3: 472-490.

Broadfoot, P. 1999. Stones from other hills may serve to polish the jade of this one: Towards a neo-comparative 'learnology' of education. Compare: A Journal of Comparative Education 29, no. 3: 217-231.

Canagarajah, A.S. (2002). A Geopolitics of Academic Writing, Pittsburgh Pa: University of Pittsburgh Press.

Cowen R and Kazamias, A. (2010) International Handbook of Comparative Education, Dordrecht: Springer

Crossley, M., P. Broadfoot and M. Schweisfurth (2007) Introduction, in Crossley, M. et al (eds), Changing educational contexts, issues and identities: 40 years of Comparative Education, London: Routledge

Dyer, C. (2005) UKFIET Newsletter, March 2005, No. 1

Eliot, T.S. (1942) Little Gidding in Collected Poems 1909-1962, Faber and Faber, London, $\mathrm{p}$.

Evans, K (2003) Uncertain Frontiers: taking forward Edmund King's world perspectives on post-compulsory education. Comparative Education Vol 39 Issue 4, pp 415-422.

Hayhoe, R., and Pan, J. (2002) Knowledge across cultures: a contribution to dialogue among civilizations. Hong Kong: Hong Kong University Press.

Higginson, J.H. (2001) The Development of a Discipline: some reflections on the development of comparative education as seen through the pages of the journal Compare, in Watson (ed) Doing Comparative Education Research: Issues and problems, Oxford: Symposium Books

McGrath, S. (2010) Education and development: thirty years of continuity and change, International Journal of Educational Development, 30, 537-543

Raggatt, P. 1984. Comparative education: Its condition and a future. Compare: A Journal of Comparative Education 14, no. 1: 3-5.

Ragin, C. C (1991). The Problem of Balancing Cases with Variables in Comparative Social Science. International Journal of Comparative Sociology, Vol. XXXII Nos. 12, pp 1-8. 
Rizvi, F. (2010) 'International students and doctoral studies in transnational spaces', in Walker, M. \& P. Thomson (eds), The Routledge Doctoral Supervisor's Companion, London: Routledge

Rust, V., Soumare, A., Pescador, O, and M. Shibuya (1999) Research strategies in comparative education, Comparative Education Review, vol. 43, no. 1, pp 86 - 106

Sawchuk P ( 2010)_Contemporary Lines of Research Inquiry:

A Comparison of Themes and Representative Models in The Sage Handbook of Workplace Learning, London: Sage

Swales, J.M. (1990) Genre Analysis: English in Academic and Research Settings, New York/Cambridge: Cambridge University Press

Watson, K. (2001) Introduction: rethinking the role of comparative education, in Watson, K. (ed) Doing Comparative Education Research: Issues and problems, Oxford: Symposium Books 